\title{
Temperature Variation Effect on a Rectangular Microstrip Patch Antenna
}

\author{
https://doi.org/10.3991/ijoe.v15i05.9755 \\ Akinwale Oluwaseyi Fadamiro ${ }^{(凶)}$, Oluwole J. Famoriji, \\ Rabiu S. Zakariyya, Fujiang Lin \\ University of Science and Technology China, (USTC) Hefei, China. \\ aofadamiro@mail.ustc.edu.cn
}

Oluwasegun Ayokunle Somefun, Erastus O. Ogunti, Waliu O. Apena, F. M. Dahunsi Federal University of Technology Akure, Nigeria

\begin{abstract}
A novel hypothesis is proposed for the sensitivity of the Rectangular Microstrip Patch Antenna (RMPA) to temperature variations under ideal room manufactured temperature tolerance. This hypothetical model equation is validated while relating the resonating frequency, patch length and dielectric constant of the rectangular patch antenna to variations from the ideal room temperature. The study considered three different substrate materials as follows; Rogers RT/Duroid 5870, FR-4 substrate and Epsilam-10 ceramic-filled Teflon used to verify the model's temperature sensitivity for the rectangular patch antenna. Simulation results revealed discrepancy in ambient temperature with respect to the dimensions of the rectangular patch antenna, field radiation patterns, power pattern and generated radiation electric field plane. The study shows substrate with a lower dielectric constant and thermal coefficient is less sensitive to temperature variations.
\end{abstract}

Keywords - Rectangular microstrip patch antenna (RMPA), sensitivity, substrates, temperature variation.

\section{Introduction}

In recent years, there has been a rapid advancement in microstrip patch antenna (MSA) for wireless and radar communication applications. MSA is in high demand considering its advantages like; easy to fabricate, low cost of production, lightweight and low profile. The MSA is an etched metallic strip on a substrate material, manufactured under room temperature conditions. Theoretically, a patch antenna is required to operate in an environment, which is either close to the room or standard conditions. In communication systems, it's important for antenna design engineers to ensure the capacity of the antenna communication component is stable and efficient in receiving or transmitting power signals under varying meteorological factors; like ambient temperature. Antennas often work in these harsh environments characterized by large temperature variations in air and spaceborne applications. However, the efficiency of 
a patch antenna depends on geographical position, ambient temperature variation, especially under the influence of solar radiations [1], [2], [17]. In large-scale integrated microwave applications, MSAs are thermally affected, leading to undesirable variations in their electrical properties. Fig. 1 and Fig. 2 [5] illustrates the behavioural characteristics of temperature variations to permittivity (dielectric constant) of its substrate material.

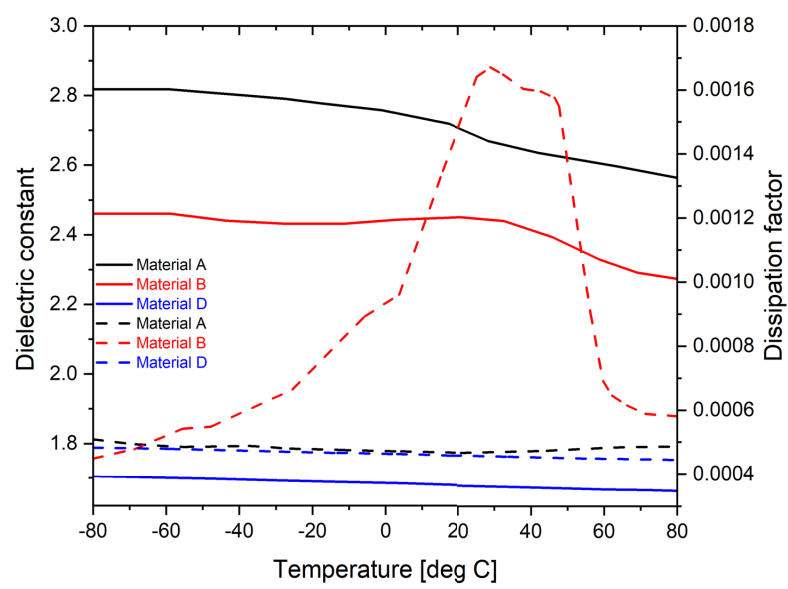

Fig. 1. Measured dielectric constant $\left(\varepsilon_{\mathrm{r}}\right)$ and dissipation factor $(\tan \delta)$ for three categories $(A$, $\mathrm{B}, \mathrm{D})$ of glass reinforced teflon laminates.

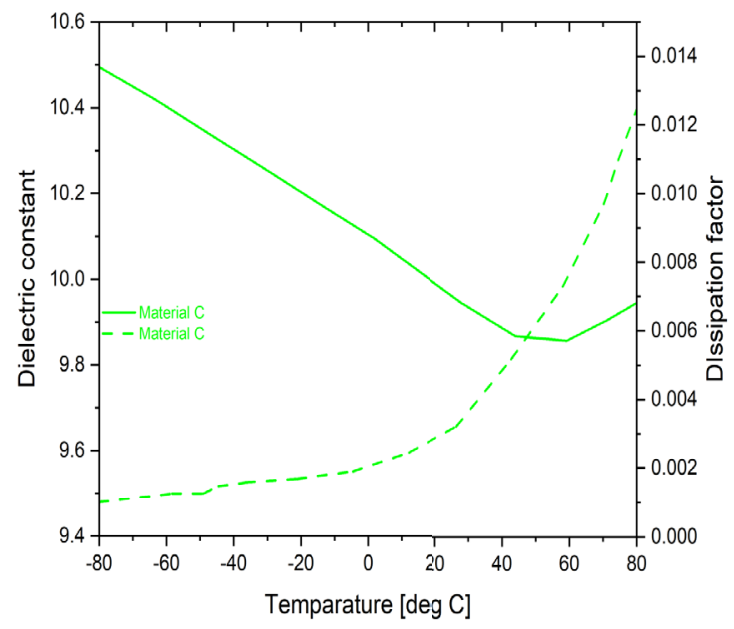

Fig. 2. Measured dielectric constant $\left(\varepsilon_{r}\right)$ and dissipation factor $(\tan \delta)$ for categories $C$ of ceramic filler laminate $\mathrm{C}$.

In the past two decades, research has been carried out to evaluate effect of temperature variations on the performance of these microstrip patch antennas with respect to 
its performance index on relationship between antenna resonant frequency shift and temperature variation with respect to the transmission line model [8]. According to [17], the dielectric constant of the patch's substrate and the physical dimensions are temperature dependent, which affects the resonant frequencies of the microstrip patch antenna. Also, [17] evaluated the effect of temperature on the resonant frequencies of microstrip patch antennas in order to adopt a microstrip patch antenna as a temperature sensor. It has been observed that the temperature response of microstrip patch antennas leads to a simpler temperature sensor, inexpensive to produce and could be examined via wireless across a long distance. Hence [18], [19] have validated the strain sensing capability of microstrip patch antennas and temperature sensing capabilities enabling temperature compensated strain measurements resulting in a robust wireless antenna strain sensor at varying environmental conditions.

Most manufacturers typically emphasize on the frequency dependence of the material, neglecting the temperature drift when providing the thermal coefficient at the temperature range from $0^{\circ} \mathrm{C}(32 \mathrm{~F})$ to $100^{\circ} \mathrm{C}(212 \mathrm{~F})$ in the datasheets [5].

Microstrip patch antenna designers rely on the data provided in the manufacturer's specifications, confined to standard environmental conditions. Practically, the electrical parameters of the substrates deviate with the temperature variation as illustrated in Fig. 1 and Fig. 2 [5], thus making the antenna designer adopt a deficient design strategy. The dielectric materials are categorized to Material A representing Ultralam 2000 and CuClad 250 LX laminates, while Material B represents RT/duroid 5880 and TLX-8 laminates. Material A and B include teflon-glass microwave laminates while C and $\mathrm{D}$ includes ceramic and quartz fiber composites respectively. The substrates are characterized by dielectric constants whose values decreased with temperature.

The rectangular configuration is the most common MSA because it's easy to analyze, fabricate and it has low cross-polarization characteristic. This study considered Transmission line model to provide better and accurate temperature relations to analyze temperature effect on the performance parameters of the rectangular microstrip patch antenna (RMSA). Adapted equations are used to simulate three test RMSA substrate cases of different relative dielectric constant and thermal coefficient of dielectric expansion. Behavioural characteristics of RMSA cases were investigated and observed under varying ambient temperatures.

This paper is organized as follows; Section 2, the theoretical design of the RMSA is presented. In Section 3, the transmission-line model analysis of the RMSA was analyzed and improved temperature equations were derived for relating the RMSA to its operating parameters. In Section 4, numeric simulations are provided to examine the radiation pattern performance of the RMSA test cases to temperature drift. Finally, some conclusions are drawn in Section 5. 


\section{RMSA Design Theory}

\subsection{Basic Design Theory}

MSAs generally consist of a very thin (thickness, $t \ll \lambda_{o}$ ) metallic strip or patch printed (photo-etched) on a small fraction of a wavelength $\left(\lambda_{0}\right)$, which represents the height of the substrate material above a ground plane, $0.003 \lambda_{o} \leq h \leq 0.05 \lambda_{o}$ [1]. The microstrip and the ground plane are separated by a dielectric surface, commonly called a substrate. The length of the rectangular patch is usually $0.333 \lambda_{o}<L<0.5 \lambda_{o}$. Different substrate materials have been employed for the design of the MSA, with their dielectric constant $\left(\varepsilon_{r}\right)$ values ranging from $2.2 \leq \varepsilon_{r} \leq 12$ range. Dielectric substrates for good antenna performance are thick materials with lower $\varepsilon_{r}$ values since they have been found to provide better efficiency and larger bandwidth. Therefore, it's essential for antenna design engineers to consider the choice of substrate very important. Although, thinner dielectric substrates with higher $\varepsilon_{r}$ are more desirable in microwave circuits because they lead to smaller element size and they have relatively smaller bandwidths. The design cost is reduced in efficiency, and greater losses are experienced. In practical applications, MSAs are mostly used in microwave applications. Hence, a compromise has to be reached to achieve good performance [3].

\subsection{Transmission-Line Model}

The RMSA physical characteristics can be illustrated as a combination of the substrate (Material A, B, C, D), height (h), patch (copper), width (w), length (l) and the ground (copper) plane. Hence, using the principles of a transmission line analysis, the RMSA can be represented by a low-impedance transmission line of length (L) [3], [7]. At a specified operating frequency $\left(f_{o}\right)$, the following optimal design parameters of the RMSA can be approximated with the following equations, provided $\frac{W}{h} \gg 1[1],[2],[3] ;$

The effective dielectric constant $\left(\varepsilon_{e}\right)$ is given by;

$$
\varepsilon_{e}=0.5\left(\varepsilon_{r}+1\right)+\frac{0.5\left(\varepsilon_{r}-1\right)}{\sqrt{1+\frac{12 h}{W}}} \propto
$$

The actual width (W) of the rectangular microstrip patch antenna;

$$
W=\frac{v_{o}}{2 f_{o}} \sqrt{\frac{2}{\varepsilon_{r}+1}} \text { a }
$$

The actual length $(L)$ of the rectangular microstrip patch antenna; 


$$
L=\frac{v_{o}}{2 f_{o} \sqrt{\varepsilon_{e}}}=\frac{\lambda_{o}}{2 \sqrt{\varepsilon_{e}}}=\frac{\lambda}{2}
$$

The extension in the length of the microstrip patch $(\delta L)$ due to fringing;

$$
\delta L=0.412 h \frac{\left(\varepsilon_{e}+0.3\right)\left(\frac{W}{h}+0.264\right)}{\left(\varepsilon_{e}-0.258\right)\left(\frac{W}{h}+0.8\right)}
$$

The effective length of the microstrip patch $\left(L_{\text {eff }}\right)$;

$$
L_{e f f}=L+2 \delta L a
$$

Practically; as a result of coupling occurrence, the resonant input slot resistance $\left(R_{\text {in }}\right)$ when there is no feed point distance $\left(y_{o}\right)$ is expressed as [3];

$$
\begin{gathered}
R_{\text {in }\left(y_{0}=0\right)}=\frac{1}{2\left(G_{1}+G_{12}\right)} \approx Z_{i n} \\
G_{1}=\frac{-2+\cos (X)+X \operatorname{Si}(X)+\sin (X) / X}{120 \pi^{2}} \\
X=k o W=\frac{2 \pi}{\lambda_{o}} W \\
X=k o W=\frac{2 \pi}{\lambda_{o}} W \\
G_{12}=\frac{\int_{0}^{\pi}\left[\frac{\sin \left(\frac{k o W}{2} \theta\right)}{\cos \theta}\right]^{2} J o(k o L \sin \theta) \sin ^{3} \theta d \theta}{120 \pi^{2}}
\end{gathered}
$$

Where;

$G_{1}=$ Self-conductance,

$G_{12}=$ Mutual-conductance,

$k o=$ Phase constant of free-space (air),

Si $=$ Sinint

$J o=$ Bessel function of the first kind of order zero.

Assuming no coupling, the input slot resistance $\left(R_{\text {in }}\right)$ when there is no feed point distance $\left(y_{0}\right)$ is given as [3];

$$
R_{\text {in }\left(y_{o}=0\right)}=\frac{1}{2 G} \approx \frac{\lambda_{o}}{0.01672 W}=Z_{\text {in }}
$$


The rectangular patch antenna is matched to a coaxial microstrip line of $50 \mathrm{ohms}$ input impedance. Hence, a feeding point distance from the radiating edge of the dimension of the patch is introduced and expressed as;

$$
\begin{gathered}
R_{i n\left(y_{o}\right)}=50 \Omega=Z_{o} \\
R_{i n\left(y_{o}\right)}=R_{i n\left(y_{o}=0\right)} * \cos ^{2}\left(\frac{180}{L} y_{o}\right)
\end{gathered}
$$

Therewith, the feeding point distance $\left(y_{o}\right)$ is derived from the edge of the microstrip line in equation (8) and its given as;

$$
y_{o}=\frac{L}{180} \cos ^{-1}\left(\sqrt{\frac{50}{R_{i n\left(y_{o}=0\right)}}}\right)
$$

\section{Method of Analysis}

Mostly, antenna temperature which is sometimes referred to as antenna noise temperature depends on the gain pattern and nature of the thermal environment its place to operate since it does not have an intrinsic temperature. The temperature of a patch antenna will vary depending on whether it's directional, pointing into space or staring into the sun [7].

\subsection{Temperature sensitivity}

Generally, it has been accepted that the operating frequency of the MSA is sensitive to large temperature variations. Hence, most RMSA operations are concerned with how temperature drift affects the resonating frequency and the bandwidth of the RMSA [17]. Since the 1990s, the effect of temperature on MSA performance has been researched considering that most manufacturers of MSAs do not often account for temperature drift. Hence, careful selection of the electrical parameters of substrate materials (dielectric constant) least sensitive to temperature variation is a prerequisite to accomplishing a satisfactory MSA performance [5]. Manufacturers design patch antennas at room temperature using absolute temperatures $27^{\circ} \mathrm{C}$ or $25^{\circ} \mathrm{C}$. Although, the ISO standard reference temperature for geometrical product specification and verification is $20^{\circ} \mathrm{C}$.

Furthermore, [6] concluded that MSAs with lower dielectric constant substrate material and thermal coefficient of dielectric-constant expansion (CTDE), are less sensitive to temperature variations. Hence; neglecting the effect of atmospheric pressure in first principles and approximation, change in temperature causes fractional changes in the dimensions of the material which is relatively small. This temperature change is referred to as thermal expansion. The expansion is linearly related to temperature change by a linear expansion constant, called the coefficient of thermal expansion 
(CTE). CTE does not change much over a varying temperature, except when the material's temperature rises past its glass transition temperature $\left(T_{G}\right)$.

In choosing materials that are resistant to temperature variations for MSA, CTE $\left(\mathrm{ppm} / \mathrm{K}\right.$ or $\left.10^{-6} / \mathrm{K} \equiv \mathrm{ppm} /{ }^{\circ} \mathrm{C}\right)$ of the substrate material and that of the metallic strip are very important. Therefore, with proper selection of the CTEs and dielectric constant, the effect of temperature drift can be made drastically negligible on the desired operating frequency. The CTDE of the substrate material is usually always higher than the CTE of the metallic strip, which is mainly copper. The expansion of the dielectric substrate material along its $\mathrm{X}$ and $\mathrm{Y}$ axes are negligible, only the expansion along the $\mathrm{Z}$ axes is considered. Hence, due to this thermal expansion, there is a contraction or expansion in the length $(\mathrm{L})$ of the metallic strip given as;

In MSAs, this expansion in length of the metallic strip has been found to induce a reduction in the resonating frequency [6] given as;

$$
\begin{gathered}
\alpha_{l t}=\frac{1}{L} \frac{\delta L}{\delta T} \\
\frac{\delta L}{L}=\alpha_{l t} \delta T \\
\frac{\delta f}{f_{o}}=-\frac{\delta L}{L}=-\alpha_{l t} \delta T
\end{gathered}
$$

Where;

$\delta f=$ change in resonant frequency;

$\delta L=$ change in effective resonant dimension;

$\alpha_{l t}=$ thermal coefficient of expansion;

$\delta T=$ temperature change in ${ }^{\circ} \mathrm{C}$.

In addition, contraction or expansion in electrical dimensions of dielectric substrate material is given as;

$$
\alpha_{s t}=\frac{1}{\varepsilon_{r}} \frac{\delta \varepsilon_{r}}{\delta T}
$$

The dielectric constant of most substrates used in microwave applications, tend to decrease with increase in temperature as presented in equation (18);

$$
\frac{\delta \varepsilon_{r}}{\varepsilon_{r}}=-\alpha_{a t} \delta T
$$

The decrease in the MSAs effective dielectric constant of the substrate material relatively increases the resonating frequency, causing a reduction effect as a result of the expansion in the patch dimensions due to the rise in temperature.

By approximation of the relationship between $\varepsilon_{e}$ and $\varepsilon_{r}$ is given as [6]; 


$$
\varepsilon_{\varepsilon} \approx 0.5 \varepsilon_{r}
$$

Where;

$$
\begin{aligned}
& \frac{\delta \varepsilon_{e}}{\varepsilon_{e}}=0.5 \frac{\delta \varepsilon_{r}}{\varepsilon_{r}}=-0.5 \alpha_{e t} \delta T \\
& \frac{\delta f}{f_{o}}=-\frac{\delta \varepsilon_{e}}{\varepsilon_{e}}=0.5 \alpha_{e t} \delta T
\end{aligned}
$$

$\delta \varepsilon_{r}=$ change in $\varepsilon_{r}$

$\alpha_{e t}=$ thermal coefficient of dielectric constant.

Combining equations (16) and (21) gives [6], [8];

$$
\frac{\delta f}{f_{o}}=\left(0.5 \alpha_{e t}-\alpha_{l t}\right) \delta T
$$

\subsection{Improved Temperature relations}

The variations in the length, dielectric constant and operating frequency are expressed in first-order differential equations (DEs). Therefore, to ascertain a general equation for the temperature variation in the MSAs, its required to integrate the equations once. This can be achieved using either the separation-of-variables method or the direct integration method. Therewith, a boundary value (initial value) conditions are applied to obtain an optimum solution as illustrated in equation (23). The optimal solutions to the rectangular patch's new dimensions, substrate's dielectric constant and operating frequency of the MSA when subjected to thermal expansion or contraction is given in equations (31), (34) and (36).

$$
\left(k f=\left\{\begin{aligned}
-0.5 \alpha_{c t}-\alpha_{i t^{\prime}} & \alpha_{s t}<0 \\
0.5 \alpha_{e t}-\alpha_{l t^{\prime}} & \alpha_{e t} \geq 0
\end{aligned}\right)\right.
$$

$k f$ will be the thermal coefficient of frequency expansion (CTFE).

$$
\begin{gathered}
\int \frac{\delta f}{f o}=k f \int \delta T \\
I n f=k f \cdot T+C \\
f=e^{k f t+c} \\
C=I n f-k f \cdot T
\end{gathered}
$$


Most MSAs are designed at room temperature $\left(T_{o}\right)$ to resonate at a particular operating frequency $\left(f_{o}\right)$. The initial variables are expressed as;

$$
\begin{aligned}
& C=\operatorname{In} f_{0}-k f \cdot T_{0} \\
& f=e^{k f f-m f_{g}-k f T_{s}} \\
& f=e^{k f\left(T-T_{o}\right)} e^{i n f o} \\
& f=f_{0} e^{k f\left(T-T_{\sigma}\right)}
\end{aligned}
$$

Hence, applying the integral and boundary conditions to the dielectric constant and operating frequency relationship using $\varepsilon_{r o}$ and $L_{o}$, as initial variables gives;

$$
\begin{gathered}
\int \frac{\delta \varepsilon_{r}}{\varepsilon_{r}}=-\alpha_{g t} \int \delta T \\
\text { In } \varepsilon_{r}=-\alpha_{g t} T+C \\
\varepsilon_{r}=\left\{\begin{array}{cc}
\varepsilon_{r o} e^{\alpha_{s t}\left(T-T_{s}\right),} & \alpha_{s t}<0 \\
\varepsilon_{r 0} e^{-\alpha_{s t}\left(T-T_{\sigma}\right)}, & \alpha_{s t} \geq 0
\end{array}\right. \\
\int \frac{\delta L}{L}=\int \alpha_{l t} \delta T \\
L=L_{0} e^{\alpha_{l t}\left(T-T_{\sigma}\right)}
\end{gathered}
$$

An optimal new rectangular patch antenna dimensions, substrate dielectric constant and operating frequency of the MSA, when subjected to thermal expansion or contraction is obtained. These improved relations were programmed and simulated in MATLAB R2018a at harsh temperature variations. The obtained results agree with experimented conclusions in [6] and are shown and discussed in section 4.

\section{Simulation of the RMSA}

A parameter often describes in specification sheets for antennas that operate in certain environments is the ratio of the antenna's gain divided by the antenna's temperature, which is referred to as radiating near field or fresnel region of the source. It's one of the important characteristics of an antenna explaining the spatial relative distribution of the antenna's power and electric field strength. This research work presents the temperature variation effect on the electric field plane, operating frequency (resonant 
frequency) and the radiation pattern of a RMSA. The field radiation pattern of the RMSA was simulated using MATLAB'S ANTENNA TOOLBOX functions.

\subsection{Simulation algorithm}

Theoretical design calculations of a RSMA [1] was adapted to analyze the antenna and the following procedures are deployed to simulate the effect of temperature variation on a RMSA in MATLAB environment as illustrated below;

Step 1. Specify ambient temperature variation

- Specify the room temperature in degree celsius.

- Set the temperature range according to the geographical environment.

- Smooth the temperature values for realistic simulation.

\section{Step 2. Input analysis}

- Input the following basic parameters of the required rectangular microstrip antenna; substrate material, relative dielectric constant of substrate, thickness of the substrate, operating frequency, desired impedance of the feed line, and coefficients of thermal expansion of the metallic strip.

- Design the rectangular microstrip patch antenna to obtain other parameters; actual dimensions of the patch, effective permittivity, ground dimensions, input impedance, inset feed location along the length of the patch, notch width, gap of the feed line, bandwidth, directivity, quality factor, magnitude of the reflection coefficient, and voltage standing wave ratio.

\section{Step 3. Calculate the design parameters as a function of Temperature Drift}

- Shift the temperature index by making room temperature index the centre point, zero.

- Get the index of the specified room temperature, lowest temperature, and highest temperature from the temperature range.

- Calculate the patch antenna's parameters due to temperature variation drift; length of patch, relative and effective permittivity of substrate, theoretical coefficient of thermal expansion of the operating frequency, resonant frequency, input impedance, new feed points from the radiating edge of the strip length, bandwidth, directivity, reflection coefficient, voltage standing wave ratio.

\section{Step 4: Analyse the rectangular patch antenna's field patterns}

- Create a realistic geometry for the patch antenna using the calculated parameters due to temperature variations.

- Plot and analyze the patch antenna's radiation pattern behaviour in terms of directivity, power and electric field strength at the selected temperatures of interest, which are; specified room temperature, lowest temperature, and highest temperature from the specified temperature range. 


\subsection{Test cases}

In this temperature variation analyses of a RMSA, copper has been used as the metallic patch material with a thickness of $0.035 \mathrm{~mm}$, and the height (h) of the substrate material is $0.8 \mathrm{~mm}$ as applicable to miniaturized designs in communication applications for the desired input impedance of $50 \mathrm{ohms}$.

The temperature sensitivity study of a RMSA was carried out on three different commercially available substrates namely; Rogers RT/Duroid 5870 [15],[20], Farnell FR-4 [16], [21], and Epsilam-10 [5]. The RMSA dimensions are in mm for each of the three tests at room temperature. The only variable in the test is the relative permittivity of the substrate material (A, B, C, D) and its coefficient of dielectric thermal expansion.

Case 1: Low $\varepsilon_{r}=2.2, f_{o}=2.45 \mathrm{GHz}$

The Rogers RT/Duroid 5870 substrate was considered at $25^{\circ} \mathrm{C}$ room temperature at the resonating frequency of $2.45 \mathrm{GHz}$. A comparative study of its operating frequency at $-10^{\circ} \mathrm{C}$ and $40^{\circ} \mathrm{C}$ is carried out with the coefficient of thermal expansion (CTE) $115 \mathrm{ppm} /{ }^{\circ} \mathrm{C}$ as illustrated in Table 1. and Fig. 3. illustrating the designed RMSA's parameters varying with temperature. The variations are negligible on its operating frequency and other performance parameters due to its low $\varepsilon_{\mathrm{r}}$.

Case 2: Medium $\varepsilon_{\mathrm{r}}=4.7, \mathrm{f}_{\mathrm{o}}=2.45 \mathrm{GHz}$

A FR-4 substrate with the coefficient of thermal expansion (CTE) of $15 \mathrm{ppm} /{ }^{\circ} \mathrm{C}$ is considered at $25^{\circ} \mathrm{C}$ room temperature. The comparative study of its operating frequency at $2.45 \mathrm{GHz}$ while varying the temperature from $-10^{\circ} \mathrm{C}$ till $40^{\circ} \mathrm{C}$ is illustrated in Table. 2 and Fig. 4 . The designed RMSA's parameters vary with temperature which is negligible on its operating frequency and other performance parameters. Comparing the temperature variation in case 1 and case 2, it's observed that case 2 has better performance and resistance to temperature changes due to the combination of an average $\varepsilon_{r}$ closer to the lower $\varepsilon_{r}$ range and low CTDE.

Case 3: High $\varepsilon_{\mathrm{r}}=10.3, \mathrm{f}_{\mathrm{o}}=2.45 \mathrm{GHz}$

Epsilam-10 substrate with the coefficient of thermal expansion (CTE) of $570 \mathrm{ppm} / \mathrm{oC}$ is considered at $25^{\circ} \mathrm{C}$ room temperature. A comparative study of its operating frequency at $2.45 \mathrm{GHz}$ varying at $-10 \mathrm{oC}$ to $40 \mathrm{oC}$ is illustrated in Table. 3 and Fig. 5. The designed RMSA's parameters varies relatively higher with temperature variation, affecting its resonant frequency (operating frequency) drastically.

It's observed that Case 3 is an example of an unstable antenna compared to the other cases because it has a higher dielectric constant which is highly affected by high temperature variation as shown in Fig. 5(h). It deviates from the operating frequency more at lower temperatures than at higher temperatures. This effect can be reduced by selecting a material with high $\varepsilon_{r}$ but lower CTDE. Comparing the three cases, it's observed that the radiation pattern slightly varies at extreme temperature variations from the room temperature of operation. Looking at the directivity pattern characteristics of each substrate, the directive gains are relatively changed by a small amount due to extreme ambient temperatures. 
Table 1. Results of temperature sensitivity study of Rogers RT5870

\begin{tabular}{|c|c|c|c|c|c|c|}
\hline Temp $\left({ }^{\circ} \mathbf{C}\right)$ & $\mathbf{L}(\mathbf{m m})$ & $\boldsymbol{\varepsilon}_{\boldsymbol{r}}$ & $\begin{array}{c}\text { Inset feed } \\
(\mathbf{m m})\end{array}$ & $\begin{array}{c}\boldsymbol{f o} \\
(\mathbf{G H z})\end{array}$ & Zin $(\mathbf{O h m s})$ & $\begin{array}{c}\text { Directivity } \\
(\mathbf{d B})\end{array}$ \\
\hline-10 & 39.76 & 2.339 & 0.012235 & 2.447 & 154.94 & 2.89 \\
\hline 25 & 39.79 & 2.33 & 0.01224 & 2.45 & 154.85 & 2.77 \\
\hline 40 & 39.80 & 2.326 & 0.012242 & 2.451 & 154.81 & 2.79 \\
\hline
\end{tabular}

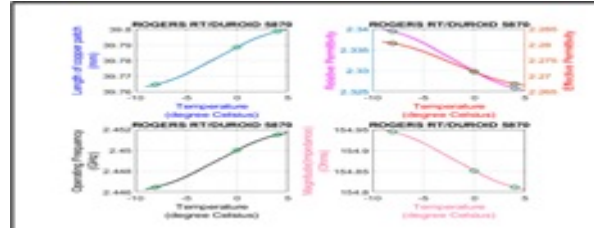

A

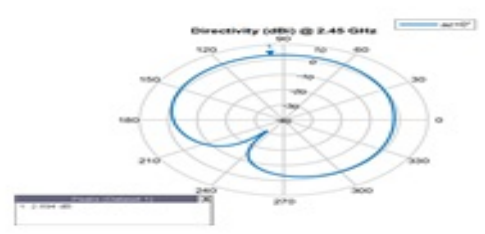

C

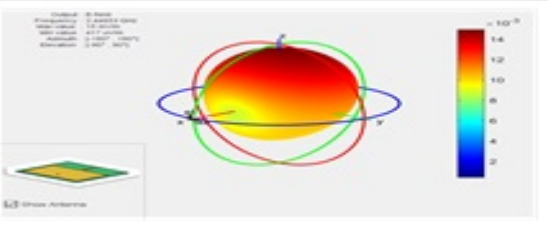

b

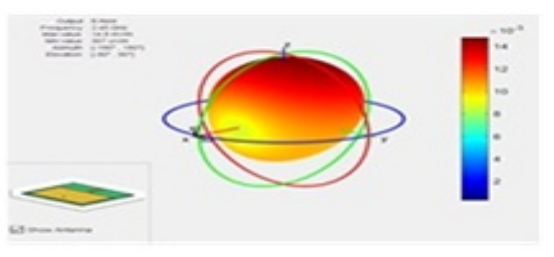

d

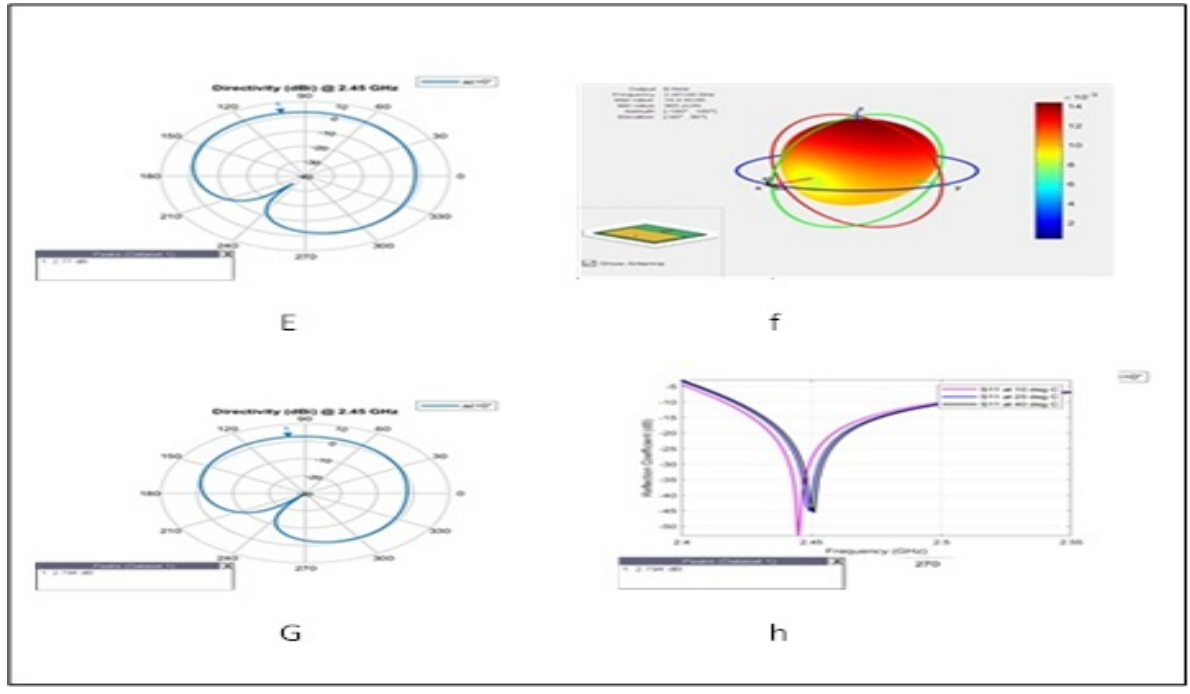

Fig. 3. Rogers RT5870; temperature variation of the RMSA. (a) Patch length, relative permittivity, operating frequency and impedance. (b) Electric-field Pattern at $-10^{\circ} \mathrm{C}$. (c) Directivity at $-10^{\circ} \mathrm{C}$ (d) Electric-field Pattern at $25^{\circ} \mathrm{C}$. (e) Directivity at $25^{\circ} \mathrm{C}$ (f) Electricfield Pattern at $40^{\circ} \mathrm{C}$. (g) Directivity at $40^{\circ} \mathrm{C}$. (h) Reflection coefficient variation at varying temperature. 
Table 2. Results of temperature sensitivity study of FARNELL-FR4

\begin{tabular}{|c|c|c|c|c|c|c|}
\hline Temp $\left({ }^{\circ} \mathbf{C}\right)$ & $\mathbf{L}(\mathbf{m m})$ & $\boldsymbol{\varepsilon}_{\boldsymbol{r}}$ & $\begin{array}{c}\text { Inset feed } \\
(\mathbf{m m})\end{array}$ & $\begin{array}{c}\boldsymbol{f o} \\
(\mathbf{G H z})\end{array}$ & Zin $(\mathbf{O h m s})$ & $\begin{array}{c}\text { Directivity } \\
(\mathbf{d B})\end{array}$ \\
\hline-10 & 28.12 & 4.702 & 0.009409 & 2.45 & 202.72 & 2.64 \\
\hline 25 & 28.14 & 4.7 & 0.009413 & 2.45 & 202.60 & 2.60 \\
\hline 40 & 28.15 & 4.699 & 0.009415 & 2.45 & 202.55 & 1.98 \\
\hline
\end{tabular}

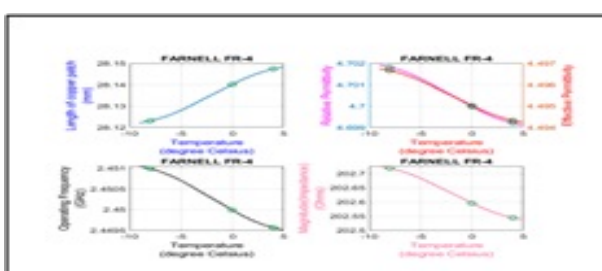

A

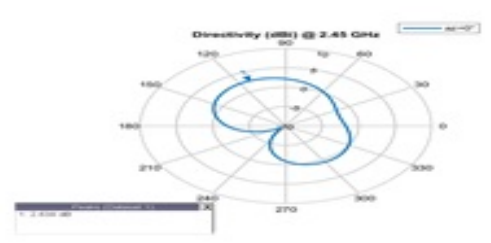

c

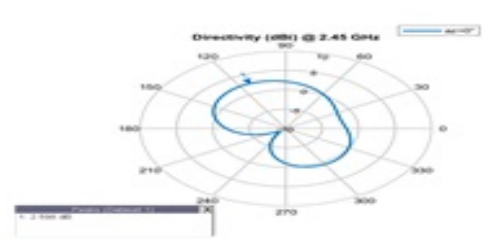

$\mathrm{E}$

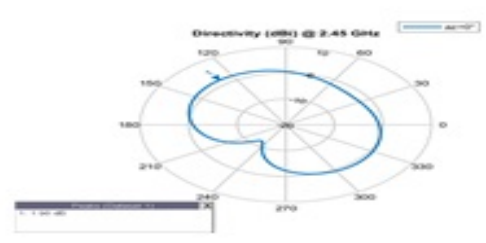

G

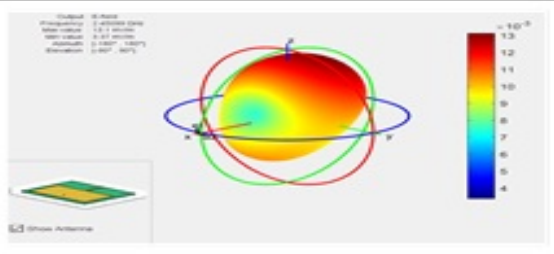

b

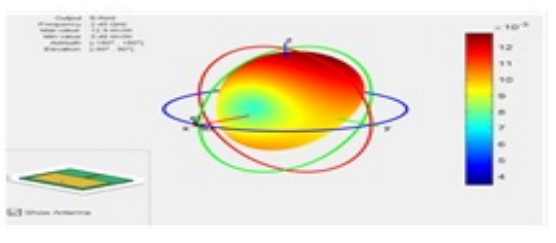

d

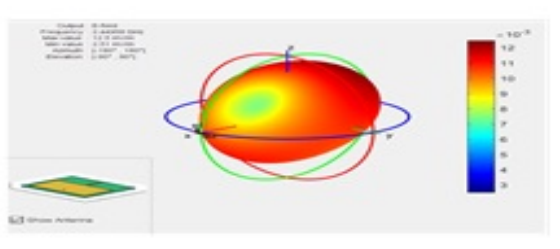

f

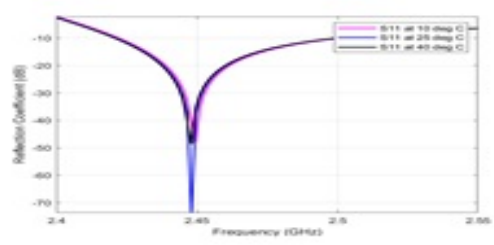

$\mathrm{h}$

Fig. 4. FARNELL-FR4; temperature variation of the RMSA. (a) Patch length, relative permittivity, operating frequency and impedance. (b) Electric-field Pattern at $-10^{\circ} \mathrm{C}$. (c) Directivity at $-10^{\circ} \mathrm{C}$ (d) Electric-field Pattern at $25^{\circ} \mathrm{C}$. (e) Directivity at $25^{\circ} \mathrm{C}$ (f) Electricfield Pattern at $40^{\circ} \mathrm{C}$. (g) Directivity at $40^{\circ} \mathrm{C}$. (h) Reflection coefficient variation at varying temperature 
Paper-Temperature Variation Effect on a Rectangular Microstrip Patch Antenna

Table 3. Results of temperature sensitivity study of EPSILAM-10

\begin{tabular}{|c|c|c|c|c|c|c|}
\hline Temp $\left({ }^{\circ} \mathbf{C}\right)$ & $\mathbf{L}(\mathbf{m m})$ & $\boldsymbol{\varepsilon}_{\boldsymbol{r}}$ & $\begin{array}{c}\text { Inset feed } \\
(\mathbf{m m})\end{array}$ & $\begin{array}{c}\text { fo } \\
(\mathbf{G H z})\end{array}$ & Zin (Ohms) & $\begin{array}{c}\text { Directivity } \\
(\mathbf{d B})\end{array}$ \\
\hline-10 & 19.04 & 10.508 & 0.006904 & 2.43 & 285.43 & 2.44 \\
\hline 25 & 19.05 & 10.3 & 0.006907 & 2.45 & 285.26 & 2.54 \\
\hline 40 & 19.06 & 10.212 & 0.006908 & 2.46 & 285.18 & 2.48 \\
\hline
\end{tabular}

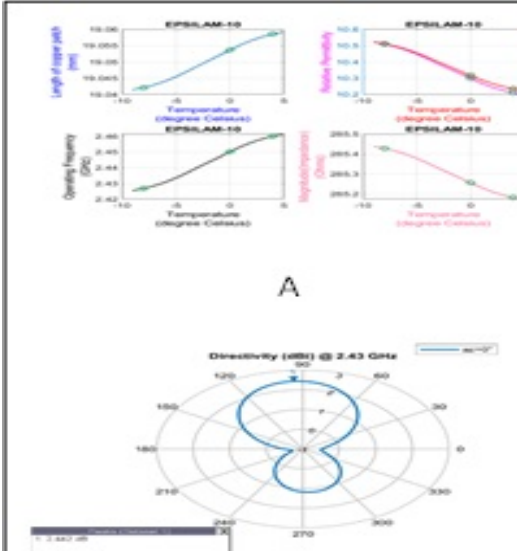

C

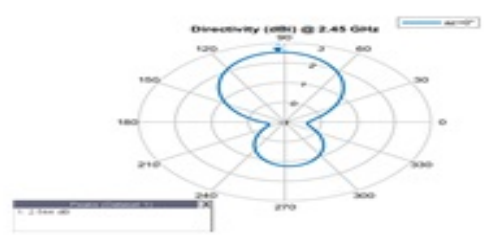

E

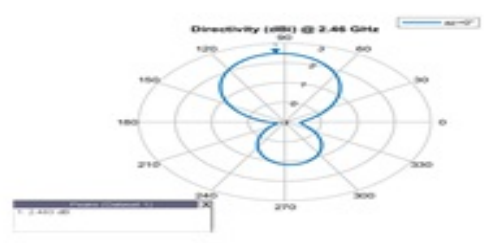

G

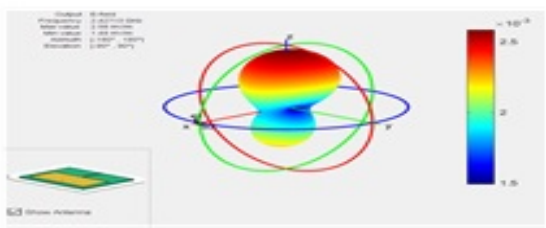

b

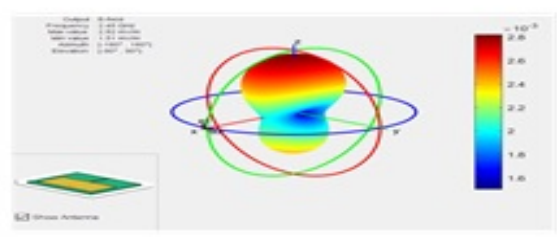

d

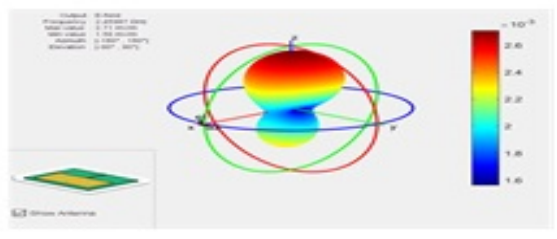

$f$

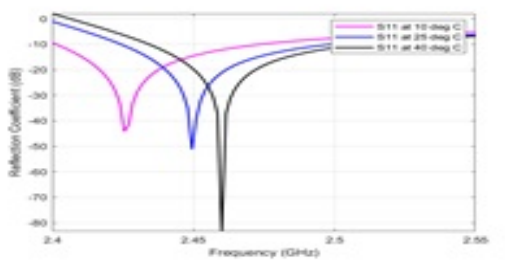

$\mathrm{h}$

Fig. 5. EPSILAM-10; temperature variation of the RMSA. (a) Patch length, relative permittivity, operating frequency and impedance. (b) Electric-field Pattern at $-10^{\circ} \mathrm{C}$. (c) Directivity at $-10^{\circ} \mathrm{C}$ (d) Electric-field Pattern at $25^{\circ} \mathrm{C}$. (e) Directivity at $25^{\circ} \mathrm{C}$ (f) Electric-field Pattern at $40^{\circ} \mathrm{C}$. (g) Directivity at $40^{\circ} \mathrm{C}$. (h) Reflection coefficient variation at varying temperature. 


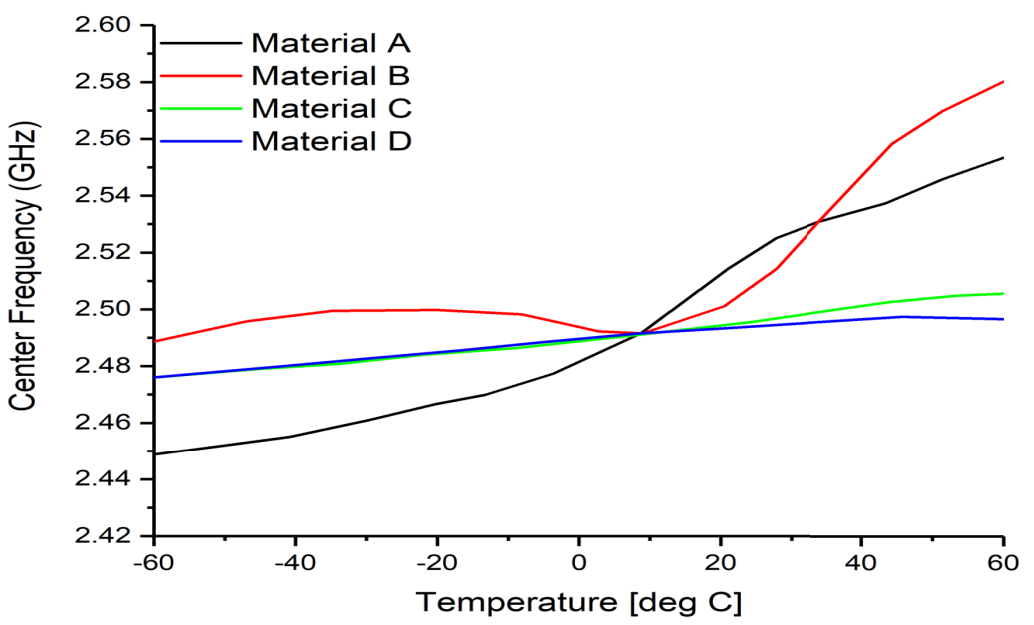

Fig. 6. Measurement result of comparison of Center frequency defined in terms of the minimum value of S11 versus temperature for antennas

The importance of evaluating the effect of thermal expansion in patch antenna design is significant to antenna design engineers as illustrated in Fig. 3 - Fig. 6. The study shows apparent change in the physical dimensions of the antenna and a slight shift in the operating frequency as illustrated in Fig. 6. The materials A, B, C, D are categorized according to their material and dielectric constants. The simulated and measured results show the slight variation experienced in temperature variation in antenna.

\section{Conclusion}

This paper presents an improved temperature relationship, simulated using MATLAB 2018a and measurement results to investigate the effect of temperature variation in RMSA. It was observed that the ambient temperature variation affects both the dimensions of the patch antenna and its radiation field patterns. The performance of the RMSA was investigated under extreme ambient temperature variations at the same operating frequency $2.45 \mathrm{GHz}$ using three material categories namely; Rogers RT/Duroid5850 (low relative permittivity), Farnell FR-4 (average permittivity), and Epsilam-10 (high relative permittivity). The analysis aligns with initial studies [5], [6] illustrating the effect of temperature variation on a rectangular patch antenna. The obtained results revealed that, electrical field and magnetic field characteristics of RMSAs on a dielectric substrate are considerably influenced by temperature variation and operational environment. Although in practice, the temperature distribution inside the antenna structure might be nonuniform. In such cases, a comprehensive analysis could be developed to consider all surrounding factors. The temperature variation analysis of the MSA is considered to be a significant factor during antenna design. 


\section{Acknowledgement}

The authors would like to acknowledge the support of Information Science Laboratory Center of USTC for software \& hardware services, MediaTek for USTC students and project sponsorship, Micro/Nano-Electronic System Integration R\&D Centre (MESIC), University of Science and Technology China; and Chinese Academy of Sciences and The World Academy of Sciences (CAS-TWAS) for their financial support.

\section{$7 \quad$ References}

[1] Abatan, A. A., Abiodun, B. J., Lawal, K. A., Gutowski W. J. (2016). Trends in extreme temperature over Nigeria from percentile-based threshold indices. International Journal of Climatology, 36(6): 2527-2540. https://doi.org/10.1002/joc.4510

[2] Climates to Travel, https://www.climatestotravel.com/climate/nigeria Accessed 02 February 2018.

[3] Balanis, C. A. (2005). Antenna Theory. Analysis and Design, 3rd ed., New York, Wiley.

[4] Bird, T. S. (2009). Definition and Misuse of Return Loss. Antennas and Propagation Magazine, 51(2): 166-167. https://doi.org/10.1109/MAP.2009.5162049

[5] Kabacik, P., Bialkowski, M. E. (1999). The Temperature Dependence of Substrate Parameters and Their Effect on Microstrip Antenna Performance. IEEE Transactions on Antennas and Propagation, 47(6): 1042-1049. https://doi.org/10.1109/8.777129

[6] Babu, S., Kumar, G. (1999). "Parametric Study and Temperature Sensitivity of Microstrip Antennas Using an Improved Linear Transmission Line Model," IEEE Transactions on Antennas and Propagation, 47(2): 221-226. https://doi.org/10.1109/8.761060

[7] Milligan, T. A. (2005). Modern Antenna Design. Wiley-IEEE Press, 2nd Edition. https://doi.org/10.1002/0471720615

[8] Yadav, R. K., Kishor, J., Yadava, R. L. (2013). Effects of temperature variations on microstrip antenna. Int. J. Netw. Commun., 3(1): 21-24.

[9] Voytovich, N. I., Ershov, A. V., Bukharin, V. A., Repin, N. N. (2011). Temperature effect on cavity antenna parameters. General Assembly and Scientific Symposium, XXXth URSI, Istanbul, Turkey. https://doi.org/10.1109/URSIGASS.2011.6050422

[10] Weiss, M. A. (1981). Temperature compensation of microstrip antennas. IEEE Antennas Propagation Soc. Int. Symp. Dig., Los Angeles, CA, 1(1): 337-349. https://doi.org/10.1109/APS.1981.1148532

[11] Ahamed, M. M. et al. (2012). Rectangular Microstrip Patch Antenna at 2GHZ on Different Dielectric constant for Pervasive Wireless Communication. International Journal of Electrical and Computer Engineering, 2(3): 417-424.

[12] Elrashidi, A., Elleithy, K., Bajwa, H. (2011). The performance of a cylindrical microstrip printed antenna for TM10 mode as a function of temperature for different substrates. International Journal of Next-Generation Networks, 3(3):1-18.

[13] Dubost, G. (1986). Linear transmission line model analysis of arbitrary shaped patch antennas. Electron. Lett., 22(15): 798-799. https://doi.org/10.1049/el:19860547

[14] Schaubert, D. H., Pozar, D. M., Adrian, A. (1989). Effect of microstrip antennas substrate thickness and permittivity, Comparison of theories with experiment. IEEE Trans. Antennas Propogat., 37(1): 677-682. https://doi.org/10.1109/8.29353 
[15] Rogers Corporation (2018). https://www.rogerscorp.com/documents/606/acs/RT-duroid5870-5880-DataSheet.pdf.

[16] Farnell (2018). https://www.farnell.com/datasheets/1644697.pdf.

[17] Sanders, J. W., Yao, J., Huang, H. (2015). Microstrip Patch Antenna Temperature Sensor, IEEE sensors journal, 15(9): 5312-5319. https://doi.org/10.1109/JSEN.2015.2437884

[18] Huang, H. (2013). Flexible wireless antenna sensor: A review. IEEE Sensors J., 13(10): 3865-3872. https://doi.org/10.1109/JSEN.2013.2242464

[19] Tata, U., Huang, H., Carter, R. L., Chiao, J. C. (2009). Exploiting a patch antenna for strain measurements. Meas. Sci. Technol., 20(1): 015201-015211. https://doi.org/10.1088/0957-0233/20/1/015201

[20] Shaikh, S. A., Tekin, I. (2015). Two axis direction finding antenna system using sumdifference patterns in X band. Microwave Optical Technology Letters. 57(9): 2085-2092. https://doi.org/10.1002/mop.29269

[21] Shaikh, S. A., Tonello, A. M. (2017). Performance Analysis of $180^{\circ}$ HRR Coupler Used for Direction Finding with an Antenna Array. International Journal of Online Engineering (iJOE), 13(10): 86-102. https://doi.org/10.3991/ijoe.v13i10.7410

\section{Authors}

Akinwale O. Fadamiro (Corresponding Author) received his B. Eng. and M. Eng. in Electrical \& Electronics Engineering, at the Federal University of Technology Akure, Nigeria. His currently studying his Ph.D. degree at the Department of Electronic Science and Technology, University of Science and Technology of China (USTC), Hefei, China. His current research interest includes; antenna design, calibration and optimization.

Oluwole J. Famoriji received his B. Eng at the Ladoke Akintola University of Technology, Ogbomoso, Nigeria and M. Eng in Electrical \& Electronics Engineering, at the Federal University of Technology Akure, Nigeria. Ph.D. degree at Department of Electronic Science and Technology, University of Science and Technology of China, Hefei, China. His research interests includes; Signal and Systems, Applied Electromagnetics, and Microwave Engineering.

Rabiu S. Zakariyya received his B. Eng at the Kano University of Science and Technology, Wudil Kano, Nigeria and M. Eng in Electrical \& Computer Engineering, at the Meliksah University Kayseri, Turkey. Currently studying his Ph.D. degree at the Department of Electronic Science and Technology, University of Science and Technology of China, Hefei, China.

Fujiang Lin received the B.S. and M.S. degrees in electrical engineering from the University of Science and Technology of China (USTC), Hefei, China, in 1982 and 1984, respectively, and the Dr.-Ing. degree in electrical engineering from the University of Kassel, Kassel, Germany, in 1993. He joined the National University of Singapore, Singapore, as a Research Scientist in 1993. In 2010, he joined the USTC as a Full Professor under the Chinese "1000 Talents Program". He is the Executive Director of the MESIC, Hefei, China, "Micro-/Nano- Electronic System Integration Research and Development Center".

Oluwasegun Ayokunle Somefun, received his B. Eng. in Electrical \& Electronics Engineering and M. Eng. in Control Engineering, at the Federal University of Tech- 
nology Akure, Nigeria. His current research interests span development of control and computational intelligence algorithms.

Erastus O. Ogunti is an Associate Professor of Electrical, Electronics \& Computer Engineering, at the Federal University of Technology Akure, Nigeria. His research interests are; electronics, micro-processor design, wireless sensor networks, MIMO OFDM, LTE networks.

Waliu O. Apena is a Senior Lecturer in Electrical, Electronics \& Computer Engineering, at the Federal University of Technology Akure, Nigeria. His expertise includes; Wireless Sensor Networks, Digital Communications, Biomedical Applications, and Knowledge Based Engineering

Folasade. M. Dahunsi is a Senior Lecturer in Electrical, Electronics \& Computer Engineering, at the Federal University of Technology Akure, Nigeria. Her research interest includes; Telecommunications, Networks and Services.

Article submitted 2018-10-24. Resubmitted 2018-12-17. Final acceptance 2018-12-24. Final version published as submitted by the authors. 